$\begin{array}{ll}\text { Research Square } & \begin{array}{l}\text { Preprints are preliminary reports that have not undergone peer review. } \\ \text { They should not be considered conclusive, used to inform clinical practice, } \\ \text { or referenced by the media as validated information. }\end{array}\end{array}$

\title{
Are there socio-demographic differences in salt behaviours and fruit and vegetable consumption in Australian adults? A nationally representative cross-sectional survey
}

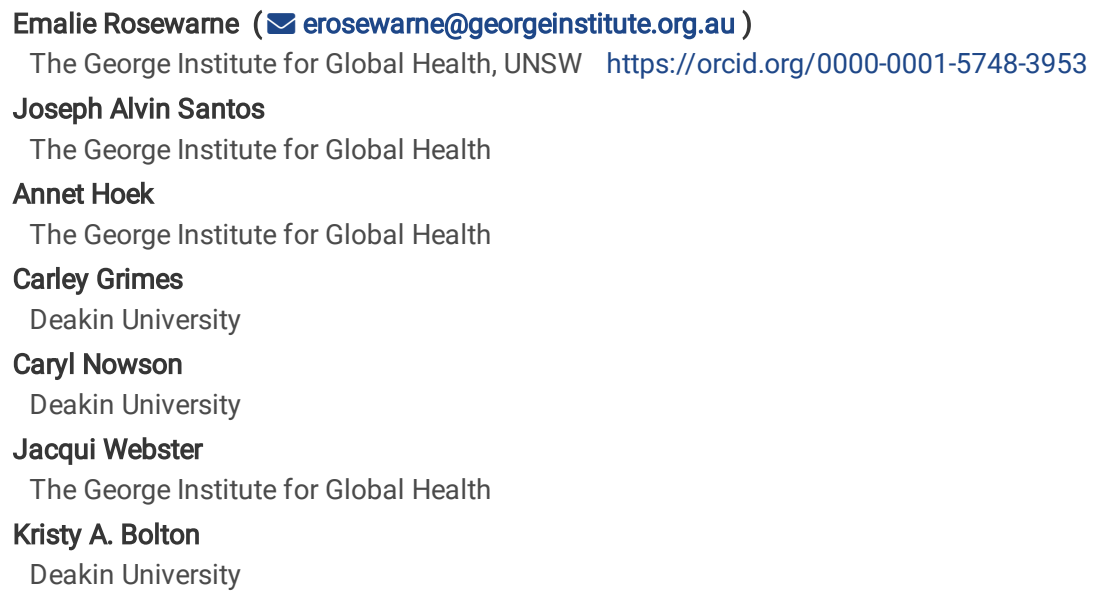




\section{Abstract \\ Background}

Diets low in fruit and vegetables and high in salt are among the top dietary risk factors for non-communicable diseases (NCDs). In a nationally representative sample of Australians, this study aimed to describe self-reported intake of fruit and vegetables, and knowledge, attitudes and behaviours related to salt intake, and determine if there were socio-demographic differences between population subgroups.

\section{Methods}

A 2016 cross-sectional survey of Australian adults aged 18 years and over, which comprised 160 questions, including socio-demographic, core health and research-related questions. Descriptive statistics (mean, 95\% confidence interval, \%) were calculated. Weighted-adjusted logistic regression models were used to determine if there were socio-demographic differences in salt behaviours and fruit and vegetable consumption.

\section{Results}

A total of 1217 participants completed the survey ( $51 \%$ female). Less than $8 \%$ of participants reported consuming the recommended 2 or more serves of fruit and 5 or more serves of vegetables. Almost $60 \%$ of participants frequently added salt during cooking/meal preparation and $42 \%$ of respondents frequently placed a salt-shaker on the table at mealtimes. There were no patterns between socio-demographic differences and measures of fruit and vegetable consumption and salt behaviours. Differences in at least one measure were found for sex, age, location, education level and weight category.

\section{Conclusions}

There were no patterns between socio-demographic factors and salt behaviours and fruit and vegetable intake. Less than recommended intakes of fruit and vegetables and frequent discretionary salt use are placing Australians at risk of diet-related NCDs. Policy changes to improve the food environment complimented by a nationwide consumer awareness campaign targeting all socio-demographic groups will therefore be required to improve Australian's diets.

\section{Introduction}

Australian diets are nutritionally imbalanced, with diets low in fruit and vegetables and high in salt among the top risk factors (1). It is estimated that only $5 \%$ of Australians are meeting the recommended guideline of 2 or more serves of fruit and 5 or more serves of vegetables per day, with just over half of Australian adults meeting the fruit guideline alone and only $7.5 \%$ meeting the vegetable guideline alone (2). For salt, Australians are consuming almost double (3) the recommended daily maximum amount of 5 grams (4), placing them at increased risk of developing high blood pressure (5). Low consumption of fruit and vegetables, and high salt intakes, increase population risk of cardiovascular diseases (CVDs), diabetes, kidney disease and some cancers (1). Together, these three dietary risk factors account for more than 11,500 deaths and almost 192,000 disability-adjusted life years in Australia each year (1).

Strategies to improve Australian diets, by increasing fruit and vegetable intake and decreasing salt intake, offer an opportunity to reduce Australia's disease burden. Strategies should include interventions to improve the food environment, through food reformulation and nutrition standards in public settings (6, 7), supplemented by programs to raise consumer awareness and positively shift consumer behaviours (8). The consumer strategy should be informed by a comprehensive understanding of the population's knowledge, attitudes and behaviours (KABs) relating to healthy diets, including fruit, vegetable and salt intakes (9). This includes whether KABs differ by population subgroups such as sex, age, location and socioeconomic background, and if specific strategies are needed to reach different groups.

Self-reported fruit and vegetable intake data are routinely collected in national health surveys, however, these data are only disaggregated by age and sex ( 2 , $10,11)$. One study in young adults aged 18-34 years determined fruit and vegetable intake differed by selected socio-demographic factors (e.g. sex, age, location) (12). It is possible these differences exist across all age groups. Another study found no difference in fruit and vegetable score by levels of socioeconomic disadvantage, education level or household income when using a using a dietary guidelines index (13). Given the varying results in past studies, further research to determine if there are socio-demographic differences in fruit and vegetable intakes in Australia is necessary.

Several studies have investigated salt-related KABs in Australia. However, most surveys have not been administered to a nationally representative sample (1421 ), and many have only included questions about two discretionary salt behaviours, adding salt at the table or during cooking/meal preparation (15-17, 21). The most recent national salt-related KAB survey, which was conducted in 2007 and comprised 23 questions, was one of only a few studies that have asked a more extensive set of questions about salt-related KABs and the only comprehensive survey in a nationally representative sample (22). Given the time elapsed since the last nationally representative survey, an update on current salt-related KABs is warranted and would be useful in informing a future national consumer campaign. When comparing the results from more recent subnational studies (14-21), large variations in participant responses were evident, likely due to the differences in sample characteristics and sampling methods. For example, the proportion of participants frequently adding salt during meal preparation varied from $46 \%$ (19) to $84 \%$ (21) and at the table from $36 \%$ (16) to $68 \%$ (14). Given the variability in participant responses between subnational studies, differences in salt-related KABs between population subgroups should be considered. In a large Victorian study, differences in salt-related KABs were identified by socio-demographic factors, including sex, age and socioeconomic status (18), and this may be true across Australia, though no study has yet investigated this. 
In a nationally representative sample of Australians, this study aimed to describe self-reported intake of fruit and vegetables and knowledge, attitudes and behaviours related to salt intake, and determine if these measures differed between socio-demographic population subgroups (i.e. sex, age, location, educational attainment, language, Indigenous status, weight category and area-level disadvantage).

\section{Methods}

\section{Participant recruitment}

This was a nationally-representative cross-sectional survey of Australian adults aged 18 years and over conducted between June and August 2016 by the Population Research Laboratory (CQUniversity) (23). Participants were recruited by a random digit dialling (both landlines and mobile lines) from a database (Sampleworx Pty Ltd) by random selection, with replacement, chosen by a computer program (23). Postcode was considered so that all respondents had an equal chance to be contacted (23). For landline phone numbers, the place of residence was pre-categorised as male or female household to also allow for equal chance to be contacted (23). If there was more than one male/female in the household, then the male/female with the most recent birthday was selected (23). If interviewers were not able to obtain a response from a household, a further five call-back attempts were made prior to moving onto the next random number in the database (23). The inclusion criteria were as follows: 18 years and over, were living in Australia and could be contacted by telephone (23).

\section{Survey instrument and methodology}

A computer-assisted telephone interviewing (CATI) survey consisting of 160 questions was administered and took participants an average of 42 minutes to complete (23). The CATI comprised three blocks of questions: Core demographic questions and core health questions drawn from previous Queensland Social Survey questionnaires (24) and other research-related questions from additional organisations (23). In this paper, we only describe survey questions as relevant to our study aim. These are included in Supplementary Table 1. A script was followed and included a brief standardised introduction followed by the three question blocks (23). The survey was pilot tested by trained interviewers in 40 randomly selected households (23). Minor adjustments were made regarding inadequate response categories, improving wording and question order following the pilot testing (23). Participant responses were directly entered into a database during the CATI (23). Quality assurance testing (random sample of 10\%) indicated that the interviews were of high quality (mean score of 8.6 out of 10), the performance of interviewers was highly rated (mean score of 9.5 out of 10 ) and the questions were easy to understand ( $81 \%$ scored mostly easy or very easy)(23).

\section{Survey data}

The CATI survey collected the following socio-demographic data: Age, sex, language spoken at home, Indigenous status, residential postcode, and educational attainment (23). Residential postcode was used to determine participant geographic locale (city, rural, town) and estimate participant level of disadvantage by the Socioeconomic Index for Areas (SEIFA) Index of Relative Socioeconomic Advantage and Disadvantage (IRSAD) (25). Self-reported data on height (cm), weight $(\mathrm{kg})$ and chronic health conditions were also collected. Height and weight were used to calculate body mass index (BMl; kg/ $\left.\mathrm{m}^{2}\right)$, and participants were then categorised as underweight $\left(<18.5 \mathrm{~kg} / \mathrm{m}^{2}\right)$, normal weight $\left(18.5-24.9 \mathrm{~kg} / \mathrm{m}^{2}\right)$, and overweight/obese $\left(\geq 25 \mathrm{~kg} / \mathrm{m}^{2}\right)(26)$.

Within the core health questions, participants were asked how many serves of fruit and vegetables they eat on a usual day, with a serve being defined in the question. Within the research-related questions, participants were asked five questions pertained to salt-related KABs, including the main source of salt in Australian diets, perceived salt intake compared to recommendations, frequency of added salt during cooking and placing a salt shaker on the table, and whether they are trying to cut down on salt intake (Supplementary Table 1).

\section{Data analysis}

Data were analysed using Stata v15.0 (StataCorp LLC, Texas, USA). To correct for over- or under-representation of certain groups in the Australian population, Population Research Laboratory (CQUniversity) created a weighting variable using age, sex and state location data from Australian Bureau of Statistics (23). All data presented are weighted data.

Descriptive statistics (mean, 95\% confidence interval, \%) for socio-demographic factors were calculated. Selected variables were collapsed into dichotomous or trichotomous variables for further analysis, including age (18-44 years, 45 years and older), Indigenous status (yes, no), education (secondary schooling or under, technical or further education, university or higher education), and weight status category using BMI (underweight, healthy weight, overweight and obesity). Responses to salt-related questions were dichotomised: main source of salt (correctly identified processed foods vs incorrect response), perceived salt consumption (more than recommended vs less than recommended, about the right amount, I don't know), and salt use behaviour questions (always/often/sometimes vs rarely/never). To enable comparison of survey data to the Australian Dietary Guidelines (27), variables were created for compliance to fruit guidelines ( $<2$ serves, $\geq 2$ serves) and vegetable guidelines ( $<5$ serves, $\geq 5$ serves).

Weighted-adjusted logistic regression models were used to determine the differences in salt behaviours and fruit and vegetable consumption by sociodemographic factors. The socio-demographic factors included in the models were: sex, age group, geographic locale, education level, language spoken at home, Indigenous status, weight category, and SEIFA quintile. One model was fitted for each of 10 outcome measures, and the adjusted proportions (or means) were derived for each socio-demographic factor post-estimation (using the margins command in Stata). A p-value of $<0.05$ was considered statistically significant. 


\begin{tabular}{|c|c|c|c|}
\hline & Total & Males & Females \\
\hline $\operatorname{Sex}(\%, 95 \% \mathrm{Cl})$ & & $49.0(45.8-52.2)$ & $51.0(47.8-54.2)$ \\
\hline \multicolumn{4}{|l|}{ Age category $(\%, 95 \% \mathrm{Cl})$} \\
\hline $18-24$ years & $12.2(9.8-15.0)$ & $12.8(9.3-17.3)$ & $11.6(8.7-15.4)$ \\
\hline $25-34$ years & $18.9(16.2-22.1)$ & $19.3(15.3-24.0)$ & $18.6(14.9-23.0)$ \\
\hline $25-44$ years & $17.7(15.3-20.2)$ & $17.8(14.6-21.7)$ & $17.5(14.3-21.1)$ \\
\hline $45-54$ years & $17.2(15.0-19.7)$ & $17.3(14.1-21.0)$ & $17.2(14.2-20.7)$ \\
\hline $55-64$ years & $14.9(13.1-16.8)$ & $14.8(12.3-17.7)$ & $14.9(12.6-17.6)$ \\
\hline 65 years and over & $19.1(17.2-21.3)$ & $18.0(15.4-21.0)$ & $20.2(17.3-23.4)$ \\
\hline \multicolumn{4}{|l|}{ State or territory currently residing in $(\%, 95 \% \mathrm{Cl})$} \\
\hline ACT & $1.5(1.0-2.3)$ & $1.7(1.1-2.6)$ & $1.3(0.6-2.9)$ \\
\hline NSW & $32.3(29.4-35.3)$ & $32.2(28.1-36.6)$ & $32.3(28.4-36.5)$ \\
\hline NT & $0.5(0.2-1.1)$ & $0.6(0.2-1.8)$ & $0.5(0.2-1.2)$ \\
\hline QLD & $20.0(17.7-22.4)$ & $20.0(16.8-23.5)$ & $20.0(16.9-23.5)$ \\
\hline SA & $7.3(5.7-9.3)$ & $7.3(5.1-10.3)$ & $7.3(5.1-10.2)$ \\
\hline TAS & $2.1(1.3-3.5)$ & $1.9(0.9-4.1)$ & $2.4(1.3-4.4)$ \\
\hline VIC & $25.3(22.8-28.1)$ & $25.2(21.6-29.2)$ & $25.4(21.9-29.3)$ \\
\hline WA & $11.0(8.6-13.9)$ & $11.2(7.6-16.3)$ & $10.8(8.1-14.3)$ \\
\hline \multicolumn{4}{|l|}{ Geographic locale (\%, 95\% Cl) } \\
\hline City & $53.6(50.3-56.8)$ & $53.8(49.0-58.5)$ & $53.3(48.9-57.7)$ \\
\hline Town & $23.4(20.6-26.5)$ & $22.8(18.6-27.7)$ & $24.0(20.5-28.0)$ \\
\hline Rural & $23.0(20.6-25.7)$ & $23.4(19.9-27.3)$ & $22.6(19.3-26.4)$ \\
\hline \multicolumn{4}{|l|}{ SEIFA (IRSAD) quintiles (\%, 95\% Cl) } \\
\hline Quintile 1 (most disadvantaged) & $13.8(11.8-16.1)$ & $12.3(9.8-15.4)$ & $15.2(12.3-18.7)$ \\
\hline Quintile 2 & $17.6(15.3-20.1)$ & $19.0(15.8-22.8)$ & $16.2(13.2-19.7)$ \\
\hline Quintile 3 & $19.3(16.8-22.0)$ & $19.7(16.1-23.9)$ & $18.9(15.6-22.6)$ \\
\hline Quintile 4 & $20.3(17.6-23.2)$ & $18.9(15.0-23.5)$ & $21.6(18.2-25.5)$ \\
\hline Quintile 5 (most advantaged) & $29.0(26.2-32.1)$ & $30.0(26.0-34.4)$ & $28.1(24.2-32.3)$ \\
\hline \multicolumn{4}{|l|}{ Highest level of education (\%, 95\% Cl) } \\
\hline Secondary school or under & $26.9(24.3-29.8)$ & $27.0(23.2-31.1)$ & $26.9(23.3-30.9)$ \\
\hline Technical or further education (TAFE) & $22.3(19.9-24.9)$ & $24.6(21.0-28.5)$ & $20.1(17.0-23.7)$ \\
\hline University or higher education & $50.8(47.5-54.0)$ & $48.5(43.8-53.2)$ & $53.0(48.6-57.3)$ \\
\hline Speaks a language other than English at home (\%, 95\% Cl) & $20.4(17.8-23.2)$ & $20.7(17.1-24.8)$ & $20.1(16.6-24.1)$ \\
\hline Identifies as an Aboriginal or Torres Strait Islander person (\%, 95\% Cl) & $1.7(1.1-2.7)$ & $1.7(0.8-3.5)$ & $1.7(0.9-3.2)$ \\
\hline \multicolumn{4}{|l|}{ Weight category $(\%, 95 \% \mathrm{Cl})$} \\
\hline Underweight & $2.8(1.7-4.5)$ & $2.5(1.1-5.4)$ & $3.0(1.6-5.7)$ \\
\hline Healthy weight & $40.8(37.7-44.0)$ & $37.7(33.2-42.5)$ & $43.8(39.5-48.2)$ \\
\hline Overweight/obese & $56.4(53.2-59.6)$ & $59.8(55.0-64.4)$ & $53.1(48.7-57.5)$ \\
\hline \multicolumn{4}{|c|}{ SEIFA: Socio-Economic Indexes for Areas; IRSAD: Index of Relative Socio-Economic Advantage and Disadvantage } \\
\hline \multicolumn{4}{|l|}{ Fruit and vegetable consumption } \\
\hline $\begin{array}{l}\text { Less than } 8 \% \text { of participants reported consuming the recommended } 2 \\
\text { meeting the fruit recommendation and only } 13 \% \text { meeting the vegetab }\end{array}$ & $\begin{array}{l}\text { f fruit and } 5 \text { or } n \\
\text { on (Fig. } 1 \text {, Supple }\end{array}$ & $\begin{array}{l}\text { ves of vegetable } \\
\text { y Table 1). }\end{array}$ & over half reported \\
\hline
\end{tabular}




\section{Ethical approval}

Ethical approval for this study was obtained from Deakin University Human Ethics Advisory Group - Health (project: 71_2016, Monitoring Salt Intake in Victoria). The 2016 National Social Survey received approval by the Human Ethics Research Review Panel at CQUniversity (project: H14/09-203, NATIONAL SOCIAL SURVEY 2016).

\section{Results}

\section{Sample characteristics}

A total of 1217 participants completed the CATI, $51 \%$ were female. The response rate (proportion of individuals participating / number of individuals invited) was $26 \%$ (23). More than half the sample were currently residing in cities (54\%) and from either NSW (32\%) or Victoria (25\%). Over $70 \%$ of participants had completed an educational qualification higher than high school. Most participants spoke English at home (79.6\%) and were non-Indigenous (98.3\%). More than half of participants were overweight or obese (56.4\%; Table 1$)$.

Table 1. Sociodemographic characteristics of weighted sample, by sex 


\begin{tabular}{|c|c|c|c|}
\hline & Total & Males & Females \\
\hline $\operatorname{Sex}(\%, 95 \% \mathrm{Cl})$ & & $49.0(45.8-52.2)$ & $51.0(47.8-54.2)$ \\
\hline \multicolumn{4}{|l|}{ Age category $(\%, 95 \% \mathrm{Cl})$} \\
\hline $18-24$ years & $12.2(9.8-15.0)$ & $12.8(9.3-17.3)$ & $11.6(8.7-15.4)$ \\
\hline 25-34 years & $18.9(16.2-22.1)$ & $19.3(15.3-24.0)$ & $18.6(14.9-23.0)$ \\
\hline $25-44$ years & $17.7(15.3-20.2)$ & $17.8(14.6-21.7)$ & $17.5(14.3-21.1)$ \\
\hline $45-54$ years & $17.2(15.0-19.7)$ & $17.3(14.1-21.0)$ & $17.2(14.2-20.7)$ \\
\hline $55-64$ years & $14.9(13.1-16.8)$ & $14.8(12.3-17.7)$ & $14.9(12.6-17.6)$ \\
\hline 65 years and over & $19.1(17.2-21.3)$ & $18.0(15.4-21.0)$ & $20.2(17.3-23.4)$ \\
\hline \multicolumn{4}{|l|}{ State or territory currently residing in $(\%, 95 \% \mathrm{Cl})$} \\
\hline ACT & $1.5(1.0-2.3)$ & $1.7(1.1-2.6)$ & $1.3(0.6-2.9)$ \\
\hline NSW & $32.3(29.4-35.3)$ & $32.2(28.1-36.6)$ & $32.3(28.4-36.5)$ \\
\hline NT & $0.5(0.2-1.1)$ & $0.6(0.2-1.8)$ & $0.5(0.2-1.2)$ \\
\hline QLD & $20.0(17.7-22.4)$ & $20.0(16.8-23.5)$ & $20.0(16.9-23.5)$ \\
\hline SA & $7.3(5.7-9.3)$ & $7.3(5.1-10.3)$ & $7.3(5.1-10.2)$ \\
\hline TAS & $2.1(1.3-3.5)$ & $1.9(0.9-4.1)$ & $2.4(1.3-4.4)$ \\
\hline VIC & $25.3(22.8-28.1)$ & $25.2(21.6-29.2)$ & $25.4(21.9-29.3)$ \\
\hline WA & $11.0(8.6-13.9)$ & $11.2(7.6-16.3)$ & $10.8(8.1-14.3)$ \\
\hline \multicolumn{4}{|l|}{ Geographic locale $(\%, 95 \% \mathrm{Cl})$} \\
\hline City & $53.6(50.3-56.8)$ & $53.8(49.0-58.5)$ & $53.3(48.9-57.7)$ \\
\hline Town & $23.4(20.6-26.5)$ & $22.8(18.6-27.7)$ & $24.0(20.5-28.0)$ \\
\hline Rural & $23.0(20.6-25.7)$ & $23.4(19.9-27.3)$ & $22.6(19.3-26.4)$ \\
\hline \multicolumn{4}{|l|}{ SEIFA (IRSAD) quintiles $(\%, 95 \% \mathrm{Cl})$} \\
\hline Quintile 1 (most disadvantaged) & $13.8(11.8-16.1)$ & $12.3(9.8-15.4)$ & $15.2(12.3-18.7)$ \\
\hline Quintile 2 & $17.6(15.3-20.1)$ & $19.0(15.8-22.8)$ & $16.2(13.2-19.7)$ \\
\hline Quintile 3 & $19.3(16.8-22.0)$ & $19.7(16.1-23.9)$ & $18.9(15.6-22.6)$ \\
\hline Quintile 4 & $20.3(17.6-23.2)$ & $18.9(15.0-23.5)$ & $21.6(18.2-25.5)$ \\
\hline Quintile 5 (most advantaged) & $29.0(26.2-32.1)$ & $30.0(26.0-34.4)$ & $28.1(24.2-32.3)$ \\
\hline \multicolumn{4}{|l|}{ Highest level of education $(\%, 95 \% \mathrm{Cl})$} \\
\hline Secondary school or under & $26.9(24.3-29.8)$ & $27.0(23.2-31.1)$ & $26.9(23.3-30.9)$ \\
\hline Technical or further education (TAFE) & $22.3(19.9-24.9)$ & $24.6(21.0-28.5)$ & $20.1(17.0-23.7)$ \\
\hline University or higher education & $50.8(47.5-54.0)$ & $48.5(43.8-53.2)$ & $53.0(48.6-57.3)$ \\
\hline Speaks a language other than English at home $(\%, 95 \% \mathrm{Cl})$ & $20.4(17.8-23.2)$ & $20.7(17.1-24.8)$ & $20.1(16.6-24.1)$ \\
\hline Identifies as an Aboriginal or Torres Strait Islander person $(\%, 95 \% \mathrm{Cl})$ & $1.7(1.1-2.7)$ & $1.7(0.8-3.5)$ & $1.7(0.9-3.2)$ \\
\hline \multicolumn{4}{|l|}{ Weight category $(\%, 95 \% \mathrm{Cl})$} \\
\hline Underweight & $2.8(1.7-4.5)$ & $2.5(1.1-5.4)$ & $3.0(1.6-5.7)$ \\
\hline Healthy weight & $40.8(37.7-44.0)$ & $37.7(33.2-42.5)$ & $43.8(39.5-48.2)$ \\
\hline Overweight/obese & $56.4(53.2-59.6)$ & $59.8(55.0-64.4)$ & $53.1(48.7-57.5)$ \\
\hline
\end{tabular}

SEIFA: Socio-Economic Indexes for Areas; IRSAD: Index of Relative Socio-Economic Advantage and Disadvantage

\section{Fruit and vegetable consumption}

Less than $8 \%$ of participants reported consuming the recommended 2 or more serves of fruit and 5 or more serves of vegetables. Just over half reported meeting the fruit recommendation and only $13 \%$ meeting the vegetable recommendation (Figure 1, Supplementary Table 1). 
There was no clear pattern between meeting fruit and vegetable recommendations and socio-demographic factors. Meeting both fruit and vegetable recommendations only differed by geographic locale $(p=0.003)$, with a much lower proportion of participants living in city areas reporting adequate serves. Meeting fruit recommendations and meeting vegetable recommendations alone differed by $\operatorname{sex}(p=0.009$ and $p=0.027$, respectively), with a higher proportion of females meeting each recommendation. A higher proportion of older and healthy weight participants reported meeting the fruit guidelines ( $p=0.002$ and $p=0.021$, respectively), and the proportion of participants meeting the vegetable recommendation was higher in more educated sub-groups ( $p=0.001 ;$ Figure 1 , Supplementary Table 1).

\section{Salt-related knowledge, attitudes and behaviours}

Eighty-five per cent of participants knew that processed foods are the main source of salt in the Australian diet and about one-third perceived their salt daily salt intake to be "more than recommended". Around a quarter reported actively trying to cut down on salt intake. Almost $60 \%$ of participants frequently (always/often/sometimes) added salt during cooking/meal preparation and $42 \%$ of respondents frequently placed a salt-shaker on the table at mealtimes (Figure 2, Supplementary Table 1).

There was no clear pattern between salt KABs and socio-demographic factors. A higher proportion of participants that were female ( $p=0.026)$, more highly educated $(p=0.001)$ and spoke English at home $(p<0.001)$ responded correctly to the knowledge question. The proportion of participants that perceived their salt intake to be more than the recommended amount was higher in males $(p=0.002)$, younger $(p<0.001)$, overweight/obese ( $p=0.025)$ and city-residing participants $(\mathrm{p}=0.031)$ (Figure 2, Supplementary Table 1).

For salt behaviours, a higher proportion of participants speaking a language other than English at home reported taking action to reduce salt intake ( $<0.001)$. A higher proportion of participants that were younger $(p<0.001)$, lived in towns $(0.014)$, and spoke a language other than English at home $(<0.001)$ frequently added salt while cooking, yet a higher proportion of older $(p=0.010)$, less educated $(p<0.001)$ and non-Indigenous participants $(p=0.029)$ placed a salt shaker on the table (Figure 2, Supplementary Table 1).

\section{Discussion}

This study found no clear pattern between socio-demographic factors and fruit and vegetable consumption and salt behaviours in a large, nationally representative sample of Australian adults. Our results confirmed that fruit and vegetable consumption and salt behaviours in Australia are poor across the adult population. As such, a nationwide consumer awareness campaign on salt, fruit and vegetables will be the most effective approach to stimulate consumer behaviour change to improve Australian's diets.

The overall salt KAB results were consistent with past research in national and sub-national samples of Australians. The majority of participants knew processed foods were the main source of salt in the Australian diet $(14,18,22)$. However, most reported frequent use of discretionary salt (10, 14-19, 21) and very few reported salt reduction actions being taken (18). These findings reinforce that Australians perform adverse salt behaviours and highlight an important opportunity for consumer education. Consumer education campaigns have been effective in reducing discretionary salt consumption at the population level (28) and an national campaign focusing on reducing discretionary salt intake could stimulate individual action to reduce salt intake and be effective in reducing salt intake by up to $25 \%$ (29). At present, only around one-quarter of participants are actively trying to reduce their salt intake. This is a much lower proportion than identified in previous sub-national samples $(18,19)$, which may reflect current consumer priorities of eating more fruit and vegetables, and less sugar and fat, before reducing salt intake (30). The low proportion of consumers currently trying to cut down on salt illustrates the potential for reducing salt intake through consumer awareness and behaviour change strategies.

Similarly, fruit and vegetable findings were consistent with previous national surveys. Around half of participants reported meeting the fruit guidelines, less than $10 \%$ reported meeting the vegetable guidelines and an even smaller proportion reported meeting both guidelines $(2,10,11)$. These results reinforce the poor fruit and vegetable intakes of Australian's and highlight the scope for consumer awareness and behaviour change strategies to improve nationwide consumption.

Differences between the findings in this study compared to non-nationally representative samples highlight the need to undertake this research to understand whether socio-demographic factors are related to salt behaviours and fruit and vegetable intake in distinct populations. There was no pattern between sociodemographic factors and fruit and vegetable consumption and salt behaviours in the current sample. The few socio-demographic differences that were identified were mostly dissimilar to those found in other samples $(12,18)$. For example, sex was not associated with discretionary salt behaviours, and was associated with attitudes regarding personal salt consumption in the current study, while the converse was true in the Victorian population (18). Also, a higher proportion of females reported consuming adequate fruit and vegetable intakes compared to males in this study, while Nour et al. determined males consumed more fruit than females and there was no difference in vegetable intake (12). These inconsistencies likely reflect the different population samples and highlight the importance of understanding if there are socio-demographic differences in a specific target population when designing consumer awareness and behaviour change strategies.

A major difference between the current study and Nour et al.'s young adults' study was the proportion meeting the fruit and vegetable guidelines. Around 15\% of young adults (18-34 years) met fruit and vegetable guidelines (12), compared to just $6.6 \%$ in the current study (18-44 years). This disparity is likely due to the different dietary methodology used. Nour et al. conducted a secondary analysis of 24-hour recall data, a subset of the Australian Health Survey data, to calculate intake of fruit and vegetables in grams per day and convert this to serves per day (12), while in the main analysis of the Australian Health Survey and the current study, self-reported serves per day was the measure used (10). This suggests that Australian's underestimate the number of serves of fruits and vegetables consumed per day compared to calculations from dietary recall data. This finding illustrates that self-reported serves per day may not be a reliable 
indicator of fruit and vegetable intake. Since this method is commonly used in population studies, for example, the World Health Organization STEPwise approach to surveillance survey (31), further research assessing the accuracy of this method is warranted.

This was the first study to investigate socio-demographic differences in measures related to salt, fruit and vegetable intake in a random and nationally representative survey sample. It allows understanding of baseline measures related to salt, fruit and vegetable intake in the population and population subgroups, which can be used to inform consumer awareness activities. The study benefited from a rigorous CATI protocol and interviewer training. However, some limitations should be noted. The National Social Survey was a lengthy self-reported questionnaire, which may be subject to participant biases (e.g.

social desirability bias) and may lead to participant and interviewer fatigue. The response rate was around one-quarter, which is low compared to the response rates of the national health surveys $(2,10,11)$. The questionnaire only included five salt questions and two fruit and vegetable questions, so while adding to the evidence base, more comprehensive surveys are required to fully understand the impact of socio-demographic variables on dietary factors including fruit, vegetable and salt intakes.

\section{Conclusion}

There was no pattern between socio-demographic factors and salt behaviours and fruit and vegetable consumption. The frequent use of discretionary salt and low indication of individuals taking action to reduce salt intake, alongside less than recommended intakes of fruit and vegetable, are placing Australians at risk of diet-related NCDs. As such, a nationwide consumer awareness campaign will likely be most effective in stimulating consumer behaviour change to improve Australian's diets. This campaign should be complemented by policies to improve the food environment to support consumers to change their behaviours.

\section{Abbreviations}

BMI: Body mass index

CATI: Computer-assisted telephone interviewing

CVD: Cardiovascular disease

DALY: Disability-adjusted life year

IRSAD: Index of Relative Socioeconomic Advantage and Disadvantage

KAB: Knowledge, attitudes and behaviours

NCD: Non-communicable disease

SEIFA: Socioeconomic Index for Areas

\section{Declarations}

\section{Ethics approval and consent to participate}

Ethical approval for this study was obtained from Deakin University Human Ethics Advisory Group - Health (project: 71_2016, Monitoring Salt Intake in Victoria). The 2016 National Social Survey received approval by the Human Ethics Research Review Panel at CQUniversity (project: H14/09-203, NATIONAL SOCIAL SURVEY 2016). This study was performed in accordance with the Declaration of Helsinki. Written informed consent was obtained from all participants prior to the interview.

\section{Consent for publication}

Not applicable

\section{Availability of data and materials}

The datasets used and/or analysed during the current study are available from the corresponding author on reasonable request.

\section{Competing interests}

J.W. is Director of the World Health Organization (WHO) Collaborating Centre on Population Salt Reduction. All other authors declare that they have no competing interests.

\section{Funding}


This study was funded by a National Health and Medical Research Council Project Partnership Grant (APP1111457). ER is supported by a University of New South Wales University Postgraduate Award (APP00889665) and George Institute Top-Up Scholarship. JAS is supported by a National Health and Medical Research Council (NHMRC) Postgraduate scholarship (APP1168948). JW is supported by a National Heart Foundation Future Leaders Fellowship II (\#102039), a NHMRC CRE on food policy interventions to reduce salt (\#1117300) and NHMRC project grants (\#1052555 and \#1111457).

\section{Authors' contributions}

All authors contributed to the design of the study. E.R., J.A.S and K.B. analysed the data. E.R. led the writing of the manuscript with support from J.A.S. and K.B. All authors contributed to the final manuscript by providing input into the interpretation of the data, reviewing, and editing the manuscript. All authors have read and approved the final manuscript.

\section{Acknowledgements}

The authors wish to thank all individuals who participated in the study.

\section{References}

1. Institute for Health Metrics and Evaluation (IHME). GBD Compare Data Visualization Seattle, WA: IHME, University of Washington; 2016 [Available from: https://vizhub.healthdata.org/gbd-compare/.

2. Australian Bureau of Statistics. 4364.0.55.001 - National Health Survey: First Results Australia 2017-18 Canberra: Australian Bureau of Statistics; 2018 [Available from: https://www.ausstats.abs.gov.au/ausstats/subscriber.nsf/0/4B3976684C09F43FCA258399001CE630/\$File/4364.0.55.001\%20\%20national\%20health\%20survey,\%20first\%20results,\%202017-18.pdf.

3. Land M-A, Nowson CA, Petersen KS, Margerison C, Neal BC, Johnson C. Salt consumption by Australian adults: a systematic review and meta-analysis. The Medical Journal of Australia. 2018;208(2):75.

4. World Health Organization. Prevention of cardiovascular disease: guidelines for assessment and management of cardiovascular risk Geneva: World Health Organization; 2007 [Available from: https://apps.who.int/iris/handle/10665/43685.

5. Graudal NA, Hubeck-Graudal T, Jürgens G. Effects of Low-Sodium Diet vs. High-Sodium Diet on Blood Pressure, Renin, Aldosterone, Catecholamines, Cholesterol, and Triglyceride (Cochrane Review). American Journal of Hypertension. 2012;25(1):1-15.

6. World Health Organization. Global Action Plan for the Prevention and Control of Noncommunicable Diseases 2013-2020. Geneva, Switzerland: World Health Organization; 2013.

7. World Health Organization. Report on the Commission on Ending Childhood Obesity Geneva, Switzerland: World Health Organization; 2016.

8. Sutherland J, Edwards P, Shankar B, Dangour AD. Fewer adults add salt at the table after initiation of a national salt campaign in the UK: a repeated crosssectional analysis. British Journal of Nutrition. 2013;110(3):552-8.

9. Khokhar D, Nowson CA, Margerison C, Bolam B, Grimes CA. Knowledge and attitudes are related to selected salt-specific behaviours among Australian parents. Nutrients. 2018;10(6):720.

10. Australian Bureau of Statistics. 4364.0.55.001 - Australian Health Survey: First Results, 2011-12 Canberra: Australian Bureau of Statistics; 2011 [Available from: https://www.ausstats.abs.gov.au/ausstats/subscriber.nsf/0/1680ECA402368CCFCA257AC90015AA4E/\$File/4364.0.55.001.pdf.

11. Australian Bureau of Statistics. 4364.0.55.001 - National Health Survey: First Results Australia 2014-15 Canberra: Australian Bureau of Statistics; 2015 [Available from:

https://www.ausstats.abs.gov.au/ausstats/subscriber.nsf/0/CDA852A349B4CEE6CA257F150009FC53/\$File/national\%20health\%20survey\%20first\%20re 15.pdf.

12. Nour M, Sui Z, Grech A, Rangan A, McGeechan K, Allman-Farinelli M. The fruit and vegetable intake of young Australian adults: a population perspective. Public Health Nutrition. 2017;20(14):2499-512.

13. Livingstone KM, Olstad DL, Leech RM, Ball K, Meertens B, Potter J, et al. Socioeconomic inequities in diet quality and nutrient intakes among Australian adults: findings from a nationally representative cross-sectional study. Nutrients. 2017;9(10):1092.

14. Charlton K, Yeatman H, Houweling F, Guenon S. Urinary sodium excretion, dietary sources of sodium intake and knowledge and practices around salt use in a group of healthy Australian women. Australian and New Zealand Journal of Public Health. 2010;34(4):356-63.

15. Grimes C, Riddell L, Nowson C. The use of table and cooking salt in a sample of Australian adults. Asia Pacific Journal of Clinical Nutrition. 2010;19(2):256-60.

16. Nowson C, Lim K, Grimes C, O'Halloran S, Land MA, Webster J, et al. Dietary Salt Intake and Discretionary Salt Use in Two General Population Samples in Australia: 2011 and 2014. Nutrients. 2015;7(12):10501-12.

17. Sarmugam R, Worsley A, Wang W. An examination of the mediating role of salt knowledge and beliefs on the relationship between socio-demographic factors and discretionary salt use: a cross-sectional study. International Journal of Behavioral Nutrition and Physical Activity. 2013;10:25.

18. Grimes CA, Kelley S-J, Stanley S, Bolam B, Webster J, Khokhar D, et al. Knowledge, attitudes and behaviours related to dietary salt among adults in the state of Victoria, Australia 2015. BMC Public Health. 2017;17(1):1-16.

19. Land M-A, Webster J, Christoforou A, Johnson C, Trevena H, Hodgins F, et al. The association of knowledge, attitudes and behaviours related to salt with 24-hour urinary sodium excretion. International Journal of Behavioral Nutrition and Physical Activity. 2014;11(1):47.

Page 9/11 
20. Grimes CA, Riddell LJ, Nowson CA. Consumer knowledge and attitudes to salt intake and labelled salt information. Appetite. 2009;53(2):189-94.

21. O'Reilly S, Brinkman M, Giles G, English D, Nowson C. Sodium intake and use of discretionary salt in an Australian population sample. Proceedings of the Nutrition Society. 2010;69(OCE1).

22. Webster J, Li N, Dunford EK, Nowson CA, Neal B. Consumer awareness and self-reported behaviours related to salt consumption in Australia. Asia Pacific Journal of Clinical Nutrition. 2010;19(4):550-4.

23. CQUniversity Australia Population Research Laboratory. 2016 National Social Survey. Final Technical \& Sampling Report. Rockhampton, Queensland: CQUniversity Australia; 2016.

24. Queensland Government Statistician's Office, Queensland Treasury. Queensland Social Survey 2018, Social Cohesion Survey Report: The State of Queensland (Queensland Treasury) 2018 [Available from: https://www.qgso.qld.gov.au/issues/2831/social-cohesion-qld-social-survey-report-2018.pdf.

25. Australian Bureau of Statistics. 2033.0.55.001 - Technical Paper. Socio-Economic Indexes for Areas (SEIFA) Canberra: Australian Bureau of Statistics; 2016 [Available from:

https://www.ausstats.abs.gov.au/ausstats/subscriber.nsf/0/756EE3DBEFA869EFCA258259000BA746/\$File/SEIFA\%202016\%20Technical\%20Paper.pdf.

26. World Health Organization Regional Office for Europe. Body mass index - BMI Copenhagen, Denmark: World Health Organization; 2020 [Available from: http://www.euro.who.int/en/health-topics/disease-prevention/nutrition/a-healthy-lifestyle/body-mass-index-bmi.

27. National Health and Medical Research Council. Australian Dietary Guidelines Canberra: National Health and Medical Research Council; 2013 [Available from: https://www.health.gov.au/sites/default/files/australian-dietary-guidelines.pdf.

28. Ide N, Ajenikoko A, Steele L, Cohn J, J Curtis C, Frieden TR, et al. Priority Actions to Advance Population Sodium Reduction. Nutrients. 2020;12(9):2543.

29. Bhat S, Marklund M, Henry ME, Appel LJ, Croft KD, Neal B, et al. A systematic review of the sources of dietary salt around the world. Advances in Nutrition. 2020;11(3):677-86.

30. IPSOS. Food CHATs. Australia's most comprehensive study integrating consumer attitudinal trends with consumption behaviour change Australia: IPSOS; 2016 [Available from: https://www.ipsos.com/sites/default/files/2016-06/023.1-Food-in-Australia.pdf.

31. World Health Organization. WHO STEPS Instrument (Core and Expanded) Geneva, Switzerland: World Health Organization; 2016.

\section{Figures}

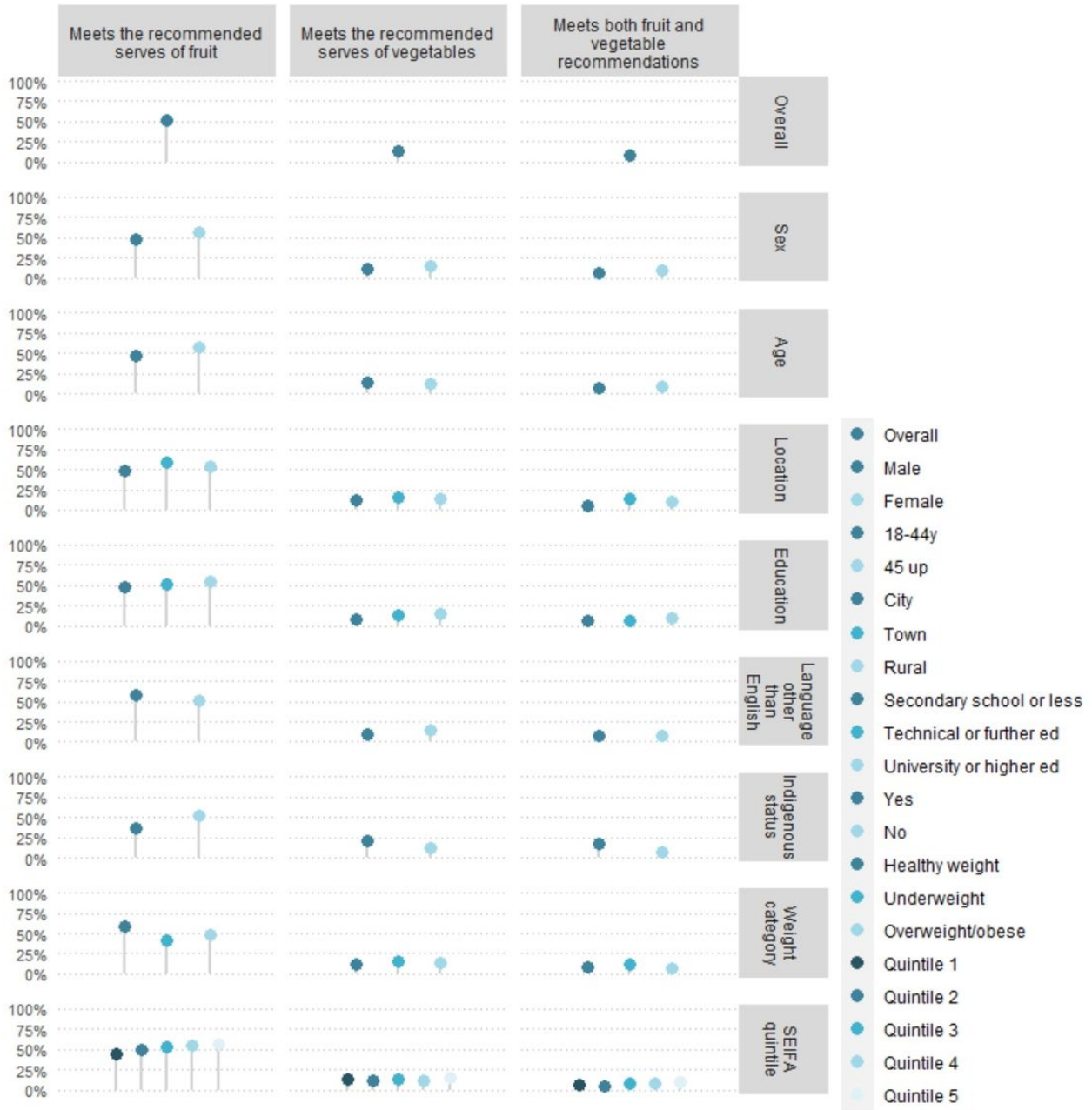

Page $10 / 11$ 
Figure 1

Fruit and vegetable consumption, overall and by socio-demographic variable

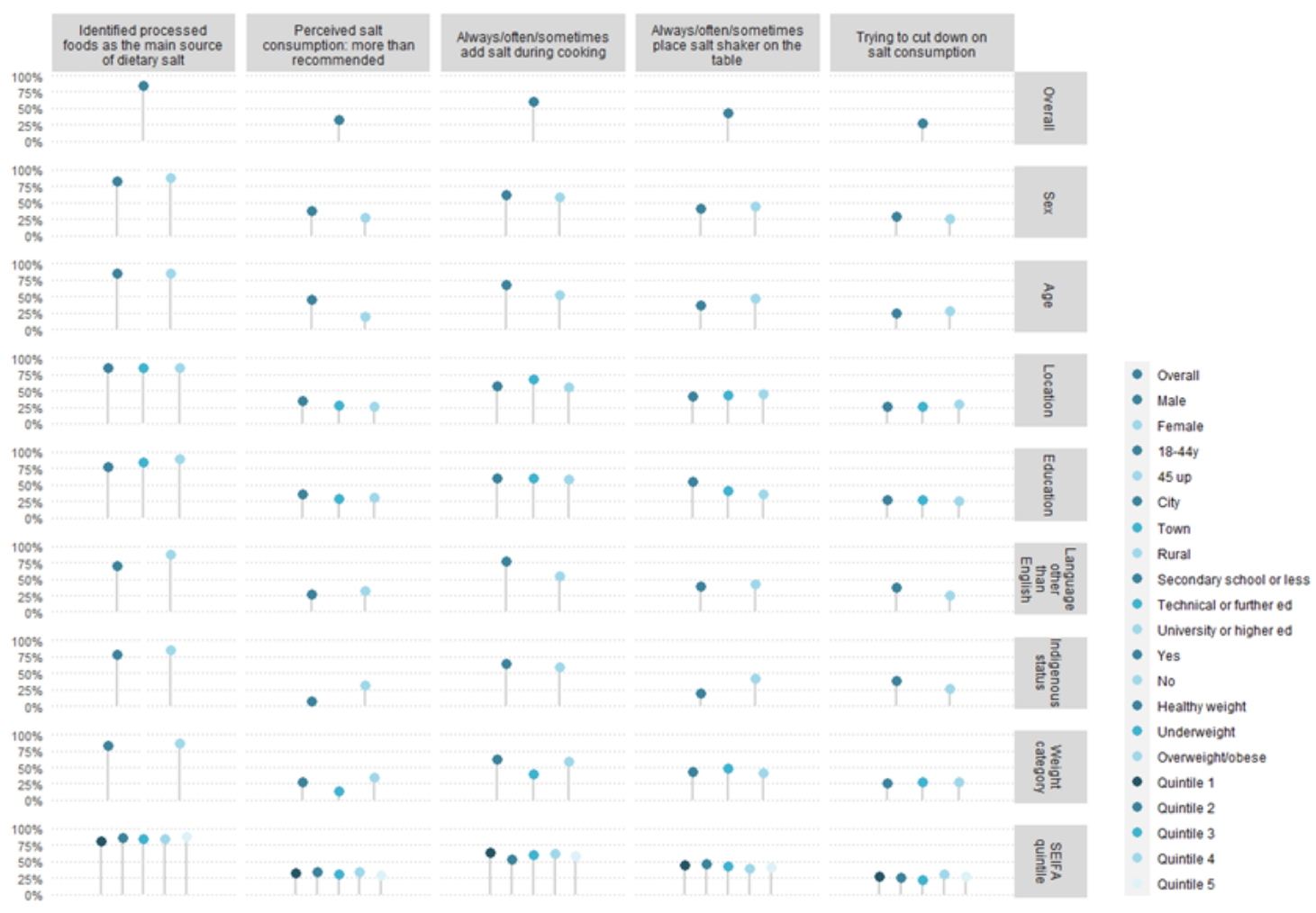

\section{Figure 2}

Salt knowledge, attitudes and behaviours, overall and by sociodemographic variable

\section{Supplementary Files}

This is a list of supplementary files associated with this preprint. Click to download.

- SupplementaryTable1.docx 